SVETLA STOILOVA, Ph.D.

E-mail: stoilova@tu-sofia.bg

Technical University of Sofia, Faculty of Transport

8 KI. Ohridski Blvd., 1000, Bulgaria
Traffic Planning

Original Scientific Paper

Submitted: 31 July 2017

Accepted: 12 Apr. 2018

\title{
AN INTEGRATED APPROACH FOR SELECTION OF INTERCITY TRANSPORT SCHEMES ON RAILWAY NETWORKS
}

\begin{abstract}
A major problem connected with planning the organization of trains on a railway network is the optimization of the scheme of movement, which determines the routing and the number of trains. In this paper, an integrated approach of fuzzy linear programming method and multi-criteria analysis including three steps is proposed. In the first step, we defined the schemes of transportation of intercity trains and optimized each scheme in terms of direct operating costs by taking into account the uncertainty of passenger flows and utilization of train capacity using the fuzzy linear programming method. In the second step we determined the additional technological criteria to assess the variant schemes. The Fuzzy AHP method was applied to determine the weights of criteria. Using the results obtained from Fuzzy AHP, we prioritized the variant schemes of transportation by applying the PROMETHEE method. The third step presents the optimal choice of transportation of trains on a railway network based on minimum ratio of normalized costs and normalized PROMETHEE net outranking flow. In this step, the model uses the results obtained in the first and second steps. The practicability of the integrated approach is demonstrated through the case study of Bulgaria's railway network, and nine schemes were investigated. The model results and the real situation were compared. It was found out that the optimal scheme of intercity train transportation improves the service and reduces direct operating costs.
\end{abstract}

\section{KEY WORDS}

fuzzy linear programming; Fuzzy AHP; PROMETHEE; train; passenger;

\section{INTRODUCTION}

An intercity transport scheme on a railway network includes the train routes, number of trains on each route, and composition of the trains. A train route is the organization of train movement between the first station and the final station. An optimal scheme of transportation is necessary to satisfy the possibilities of the railway operator and the needs of the passengers. On the one hand, it is important for railway operators to determine the optimal parameters of the organization of intercity trains taking into consideration the operating costs. However, realization of such services does not always satisfy the needs and requirements of passengers. On the other hand, for passengers, the main factors for the transport service quality are speed, direct journey, service frequency, and ticket price. An important task for passenger transport organization in a railway network is to determine the optimal scheme of movement of intercity trains. To satisfy passenger requirements and utilize the capacity of the rail operator for organization of intercity rail transport, it is necessary to examine the different quantitative and qualitative criteria which affect the choice of transport scheme for intercity trains on a railway network. Development of an optimal transport scheme is related to preliminary study of passenger flow, utilization of train capacity, and transport demand. Usually, passenger flows are determined by sold tickets or by counting. To deal with the variability of passenger flows and train capacity utilization, they can be presented as fuzzy variables.

The fuzzy sets theory allows for description of real situations, taking into account the uncertainty of the processes. The fuzzy linear programming approach (FLP) allows compiling a mathematical model to increase the adequacy of the optimization and finding solutions which are more satisfactory for the real problem, and it can be represented by fuzzy sets. Many researchers have considered various types of FLP problems and proposed several approaches for solving them $[1,2]$.

In railway transport, fuzzy linear optimization is used for rescheduling a high-speed railway timetable under unexpected interferences [3]; solving the train pathing problem; determining the admissible maximum tonnage of trains in the planning stage [4]; optimal allocation of passenger train services on an intercity high-speed rail line, including the train stop schedule, service frequency, and fleet size [5]. Fuzzy linear programming is applied also to carry out research in transport to solve transportation problems [6], as well as in transport planning [7].

A multi-criteria analysis allows for the evaluation of different alternatives based on both quantitative and qualitative indicators. Multi-criteria analysis methods such as Analytic Hierarchy Process (AHP), Fuzzy AHP (FAHP), and Preference Ranking Organization Method for Enrichment Evaluations (PROMETHEE) are applied in many areas of scientific research, including logistics and transportation. The Fuzzy AHP (FAHP) method 
makes it possible to take into account uncertainties using fuzzy numbers to compare the importance of alternatives or criteria.

In transportation, the Fuzzy AHP and PROMETHEE methods have been used for transportation mode determination, transport project evaluation, route selection $[8,11,13]$, and logistics systems $[9,10]$. In [12], the Fuzzy AHP method was used to assess three timetables for train services on the Iran rail network. The speed, reliability, capacity, cost, and safety factors are prioritized. The timetable alternatives chosen were the sum of weighted waiting times, the average of unit waiting time, and the maximum ratio of waiting time to journey time. In [14], theindicators (no ') safety, rapidity, time, and comfort are used to analyze the qualitative factors which impact the operation efficiency of highway passenger transport enterprises. In [15], a questionnaire with 23 questions was applied to investigate the passengers' satisfaction.

The present paper aims to propose an integrated approach based on the fuzzy linear programming method and the combined multi-criteria method. The fuzzy linear programming method is applied to optimize the transportation scheme of intercity trains in terms of direct operating costs. The fuzzy numbers are applied for passenger flows and utilization of train capacity. The multi-criteria combined modelling is used to determine the weights of quantitative and qualitative criteria related to the transport process and to prioritize the variant schemes. The decision for optimal scheme selection is taken based on of the results of both fuzzy linear programming and multi-criteria methods. This approach makes it possible to take into consideration the railway operator's capabilities and passengers' needs. The object of the study is the railway network of Bulgaria.

\section{RESEARCH METHODOLOGY}

The methodology includes three steps. The first step presents the criterion of minimum direct operating costs to determine the number of trains for the railway network transportation scheme. This step is aimed at satisfying the need of the railway operator to determine the optimal parameters of intercity train organization by taking into consideration the operating costs. In the second step, the assessment criteria for the variant schemes are determined, and a combination of multi-criteria analysis methods is applied. This step is aimed at satisfying the passengers' needs. The Fuzzy AHP method is used to define the weights of the criteria. Using the results, the PROMETHEE method is applied for ranking the variants schemes. In the third step, the results obtained from the fuzzy linear optimization model and combined Fuzzy AHP-PROMETHEE method are applied to select an optimal transport plan. The optimal choice of transportation of trains on a railway network is based on the selection of a scheme with a minimum ratio of normalized direct operating costs to the normalized PROMETHEE score.

\subsection{Step 1: Fuzzy linear optimization model}

The model has been developed with the following assumptions: there is no limit to the number of rolling stock; the necessary staff for train service is not a subject of the research; the number of compositions required to service the timetable is not a subject of the research.

The objective function is:

$$
\begin{aligned}
& R_{f}=\sum_{q=1}^{n} \sum_{i q f}^{I_{q f}} r_{i q f} \cdot x_{i_{q f}} \rightarrow \min \\
& R_{\text {opt }}=\min \left\{R_{1}, \ldots, R_{f}\right\}
\end{aligned}
$$

where: $R_{f}$ is the direct operating costs for scheme $f$, BGN/day. $f$ is the number of variant scheme, $f=1, \ldots, F$; $q=1, \ldots, n$ is the number of train category; $i_{q f}=1, \ldots, I_{q f}$ is the number of routes for train category $q$ for variant scheme $f ; r_{i_{q f}}$ are the direct operational costs for trains on route $i$, category $q$, and variant scheme $f$, BGN/km; $x_{i q f}$ is the number of trains on route $i$, category $q$, and variant scheme $f$.

Objective function 1 defines the optimal plan that provides the realization of the required passenger transportation with minimal direct operational costs.

The restrictive conditions are:

$$
\begin{aligned}
& \sum_{i_{q f}=1}^{I_{q f}} x_{i_{q f}} \cdot \widetilde{\alpha}_{i_{q f}} \cdot a_{i_{q f}} \cdot \gamma_{j k} \geq \widetilde{P}_{j k, q} \\
& \sum_{q=1}^{n} \sum_{i_{q f}=1}^{I_{q f}} x_{i_{q f}} \cdot \gamma_{j k}<N_{j k, \max } \\
& x_{i_{q f}} \geq M_{i_{q f}} \\
& x_{i_{q f}} \geq 0
\end{aligned}
$$

where: $\widetilde{\alpha}_{i_{q f}}$ - passenger train capacity utilization coefficient; $a_{i q f}$ - the number of seats on a train; $\gamma_{j k}$ - the coefficients that take into account the possibility of a passenger train on route $i$ to serve the section formed between two adjacent stations $j$ and $k ; \widetilde{P}_{j k, q}$ - fuzzy quantities of passenger flow in a section formed between the two adjacent stations $j$ and $k$, which will use the trains on route $i$, category $q$, that are modeled by fuzzy numbers of the highest and lowest acceptable levels, pass./day; $N_{j k \text { max }}$ - the maximum capacity of the railway line between the two adjacent stations $j$ and $k$ which are being examined, train/day; $M_{i q f}$ - the minimal number of trains for route $i$, category $q$, and variant scheme $f$, train/day.

Condition 3 means ensuring a seat for each passenger on any section of the railway network. Condition 4 means that the number of trains must not exceed the maximum capacity of the railway line. Condition 5 means that, for some routes, serving major 
transportation hubs, which are regional administrative centers, it is necessary to achieve a certain frequency of transport links. Condition 6 means that the number of trains must be positive and integer.

The fuzzy linear programming method assumes that objectives and constraints in an imprecise and uncertain situation can be represented by fuzzy sets in fuzzy programming. The fuzziness of available resources is represented by the membership functions over the tolerance range. This present research uses linear membership functions.

For the objective function $R_{f}$ it can be expressed as:

$\mu_{R_{f}}=\left\{\begin{array}{lll}1, & \text { if } \quad R_{f} \leq R_{f, L} \\ \frac{R_{f, U}-R_{f}}{R_{f, U}-R_{f, L},}, & \text { if } \quad R_{f, L} \leq R_{f} \leq R_{f, U} \\ 0, & \text { if } \quad R_{f} \geq R_{f, U}\end{array}\right.$

where: $R_{f, U}, R_{f, L}$ - highest and lowest acceptable levels of the objective that can be obtained with individual optimization.

For Constraint 3 the membership functions are:

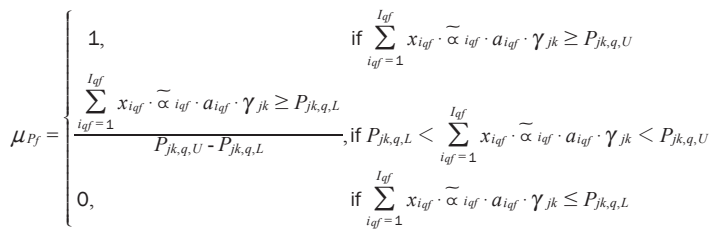

where: $P_{j k, q, U}, P_{j k, q, L}$ are the highest and lowest acceptable levels of the fuzzy quantities of passenger flow in a section formed between the two adjacent stations $j$ and $k$, that will use trains on route $i$, category $q$; pass./ day.

The fuzzy linear programming model is solved by introducing a new variable, $\lambda$. The mathematical model for the fuzzy linear programming approach which is solved by using membership functions for the investigated problem is:

$\max \lambda$

$\lambda \leq \mu_{R_{f}}=\frac{R_{f, U}-R_{f}}{R_{f, U}-R_{f, L}}$,

for objective function

$\lambda \leq \mu_{P_{f}}=\frac{\sum_{i_{q f}=1}^{I_{q f}} x_{i q f} \cdot \widetilde{\propto}_{i_{q f}} \cdot a_{i q f} \cdot \gamma_{j k} \geq P_{j k, q, L}}{P_{j k, q, U}-P_{j k, q, L}}$

for each fuzzy constraint 3

$0 \leq \lambda \leq 1$

and Constraints 4-6.

Triangular fuzzy numbers for the passenger train capacity utilization coefficient are set for each route.

$\alpha_{i_{q f}}=\left(\alpha_{i_{q f}}^{l}, \alpha_{i_{q f}}^{m}, \alpha_{i_{q f}}^{u}\right)$ where: $\alpha_{i_{q f}}^{l}, \alpha_{i_{q f}}^{m}, \alpha_{i_{q f}}^{u}$ are respectively the lower limit, fuzzy mode, and upper limit of the triangular fuzzy numbers.

The membership function for triangular fuzzy numbers is:

$\mu_{\alpha_{i 1}^{F T}}= \begin{cases}0, & \text { if } \quad \alpha_{i_{q f}} \prec \alpha_{i_{q f}}^{l} \\ \frac{\alpha_{i_{q f}}-\alpha_{i_{f f}}^{l}}{\alpha_{i_{q f}}^{m}-\alpha_{i_{q f}}^{l}}, & \text { if } \quad \alpha_{i_{q f}}^{l} \leq \alpha_{i_{q f}} \leq \alpha_{i_{q f}}^{m} \\ \frac{\alpha_{i_{f}}^{u}-\alpha_{i_{q f}}}{\alpha_{i_{q f}}^{u}-\alpha_{i_{q f}}^{m}}, & \text { if } \quad \alpha_{i_{q f}}^{m} \leq \alpha_{i_{q f}} \leq \alpha_{i_{q f}}^{u} \\ 0, & \text { if } \quad \alpha_{i_{q f}} \succ \alpha_{i_{q f}}^{u}\end{cases}$

The following formula is used for defuzzification, which transforms triangular fuzzy numbers into crisp numbers:

$\alpha_{i_{q f}}=\frac{\alpha_{i_{q f}}^{l}+\alpha_{i_{q f}}^{m}+\alpha_{i_{q f}}^{u}}{3}$

\subsection{Step 2}

\subsubsection{Determination of the additional criteria to assess variant schemes}

The second step of the methodology determines the additional criteria to assess variant schemes of intercity train transportation. These criteria are related to the benefits to the passenger. The following quantitative and qualitative criteria are applied in the research:

$K_{1}$ - Transport satisfaction, trains/day. This factor indicates the number of trains for the variant scheme and is a measure of the frequency of service. The frequency of trains attracts more passengers and creates convenience when choosing a trip at the desired time of day.

$K_{2}$ - Average number of train stops. This factor indicates the frequency of service to the settlements for the variant scheme. Express intercity (direct) trains with reduced stops attract passengers over long distances and reduce travel time. Large railway junctions are serviced by all categories of passenger trains.

$K_{3}$ - Average distance traveled, $\mathrm{km}$. This factor indicates the average length of itineraries for the variant scheme. Increase of average distance traveled for the variant scheme indicates the presence of express (direct) transport services.

$K_{4}$ - Average speed, $\mathrm{km} / \mathrm{h}$. This factor indicates the speed of transport services for the variant scheme. It takes into account the time spent by passengers on traveling considering the categories of trains.

$K_{5}$ - Reliability. In the study, reliability is given by average train delays. The delays are investigated with the duration up to 30 minutes. Reducing this coefficient leads to increased reliability. 
$K_{5}=\frac{\sum_{i=1}^{n} N_{i} \cdot k_{i}}{\sum_{i=1}^{n} N_{i}}$

$k_{i}=\frac{\frac{N_{i}^{d}}{\sum_{i=1}^{n} N_{i}}}{\sum_{i=1}^{n} \frac{N_{i}^{d}}{\sum_{i=1}^{n} N_{i}}}$

where: $k_{i}$ is the coefficient representing the delay of trains from itinerary $i ; N_{i}^{d}$ is the number of delayed trains from itinerary $i$, trains /day; $N_{i}$ is the number of trains from itinerary $i$, trains /day.

$K_{6}$ - Availability of direct transport service. Direct transport means direct train service (without intermediate stops) between large cities (over 100 thousand inhabitants). This criterion is expressed by an index. If the variant scheme offers such service, $K_{6}=1$, otherwise $K_{6}=0$. The availability of direct transport satisfies the rapid transport needs of passengers from major transport hubs.

$K_{7}$ - Transport capacity. This indicates the number of seats offered by the variant scheme per day. The number of seats depends on the number of cars in the train composition. Therefore, at the same frequency of trains, the number of seats is different. The number of seats is important for meeting passengers' transport needs.

\subsubsection{Fuzzy Analytic Hierarchy Process (FAHP)}

The study uses the FAHP methodology to determine the weights of the criteria. This method has been designed for decision-making and selecting the best alternatives by integrating the concept of fuzzy set theory and hierarchical structure analysis. The consistency ratio in the AHP and FAHP methods for assessing expert answers and a sensitivity analysis of the solutions allow using the mathematical approach to verify the obtained results. The advantage of the FAHP method is that experts provide three assessments according to the triangular fuzzy scale, which reduces subjectivity. This research adopts Chang's extent approach to FAHP [17] for evaluation, which uses a pairwise comparison scale based on triangular fuzzy numbers and the method of extent analysis. This method is relatively easier and can be presented in several stages [17].

Stage 1. Define the problem, the overall goal that has to be attained, criteria, sub-criteria, if necessary alternatives too. Define the hierarchy structure from the top level through the intermediate levels, which contain the criteria and sub-criteria, to the lowest level, which is related to the alternatives.

Stage 2. Utilization of triangular fuzzy numbers (TFN) for pairwise comparison using the FAHP scale presented in Table 1. The fuzzy evaluation matrix of the criteria $\widetilde{A}=\left(\widetilde{a}_{i j}\right)_{n, n}$ for $i, j=1, \ldots, n ; i \neq j$ is constructed through pairwise comparison of different attributes relevant to the overall objective using the linguistic variables and triangular fuzzy numbers - they are the least possible value $(l)$, the most possible value $(m)$, and the largest possible value $(u)$.

Table 1 - Triangular fuzzy scale

\begin{tabular}{||l|c|c||}
\hline \multicolumn{1}{|c|}{$\begin{array}{c}\text { Linguistic scale for } \\
\text { importance }\end{array}$} & $\begin{array}{c}\text { Fuzzy } \\
\text { number }\end{array}$ & $\begin{array}{c}\text { Triangular } \\
\text { fuzzy scale } \\
(l, m, u)\end{array}$ \\
\hline \hline Just equal & 1 & $(1,1,1)$ \\
\hline Equally important & 1 & $(1,1,3)$ \\
\hline Intermediate & 2 & $(1,2,4$ \\
\hline Weakly important & 3 & $(1,3,5)$ \\
\hline $\begin{array}{l}\text { Essential or Strongly } \\
\text { important }\end{array}$ & 5 & $(3,5,7)$ \\
\hline Very strongly important & 7 & $(5,7,9)$ \\
\hline Extremely preferred & 9 & $(7,9,9)$ \\
\hline Reciprocal value & & $(1 / u, 1 / m, 1 / l)$ \\
\hline \hline
\end{tabular}

Stage 3. In this stage, an extent analysis is made using the extent analysis method in order to obtain priority weights by using synthetic extent values. The extent analysis can be expressed as follows:

Step 1: Determining any matrix relative weight.

Step 2: Making a comparison between two triangular fuzzy numbers.

Step 3: Determining the degree of possibility for a convex fuzzy number.

After this step, the consistency ratio is calculated, and its value is checked. The consistency ratio is found with the following formula:

$C R=\frac{C I}{R I} \leq 0.1$

where: $C R$ is the consistency ratio; $C I$ is the consistency index; $R I$ is a random index. The random index is given by Saaty [18].

If the $C R$ is much greater than 0.1, the judgments are unreliable, the pairwise comparison is valueless, and it must be repeated. The consistency index is:

$C I=\frac{\lambda_{\max }-n}{n-1}$

where: $\lambda_{\max }$ is the maximum eigenvalue of the priority matrix, $n$ is the number of elements in the matrix.

$\lambda_{\max }=\sum_{i=1}^{n}\left[\left(\sum_{j=1}^{n} a_{i j}\right) \cdot W_{i}\right]$

$W_{i}=\frac{1}{n} \cdot \sum_{j=1}^{n} \frac{a_{i j}}{\sum_{i=1}^{n} a_{i j}}$

The fuzzy eigenvalue $\lambda_{l}, \lambda_{m}, \lambda_{u}$ corresponds to the maximum eigenvalue of the priority matrix $\lambda_{\text {max }}$ by AHP method. They are determined separately using crisp matrices $A_{l}, A_{m}, A_{u}$ and weights $W_{l}, W_{m}, V_{u}$ by 20 and 21. 
In this research, the eigenvalue is calculated for the weighted mean method. The TFN can be defuzzied to a crisp number through the weight mean method with the following equation:

$\widetilde{A}_{\text {crisp }}=\lambda_{\max }=\frac{\lambda_{l}+4 \lambda_{m}+\lambda_{u}}{6}$

\subsubsection{PROMETHEE method for ranking variant schemes}

After determining the weights of the criteria, the PROMETHEE methodology is applied for ranking the investigated countries. The weights of the criteria determined by means of FAHP are used in the PROMETHEE method to estimate the alternatives. This method is based on a pairwise comparison of possible decisions along each criterion. Possible decisions are evaluated according to different criteria, which have to be maximized or minimized. The use of the PROMETHEE method requires two additional types of information for each criterion $i$ : a weight $w_{i}$ and a preference function $P_{i}(a, b)$. Preference function $P_{i}(a, b)$ depends on a pairwise difference between the evaluations $f_{i}(a)$ and $f_{i}(b)$ of the alternatives $a$ and $b$ for criterion $i$. The preference function characterizes the difference for a criterion between the evaluations obtained by two possible decisions into a preference degree ranging from 0 to 1 . To facilitate the definition of these functions, six basic preference functions have been proposed - usual criterion; quasi criterion; criterion with linear preference; level criterion; criterion with linear preference and indifference area; Gaussian criterion. The explanation and mathematical calculation steps of the PROMETHEE method are summarized below [14, 16, 19]:

Step 1: This step computes, for each pair of possible decisions and each criterion, the value of the preference degree.

Step 2: This step consists of aggregating the preference degrees of all criteria for each pair of possible decisions. For each pair of possible decisions, a global preference index $\pi(a, b)$ has to be calculated.

$\pi(a, b)=\frac{\sum_{i=1}^{n} w_{i} \cdot P_{i}(a, b)}{\sum_{i}^{n} w_{i}}$

where: $i=1, \ldots, n$ is the number of criteria.

Step 3: This step is the first phase in determining the ranking of the criteria for each of the alternatives. It concerns the ranking of the possible decisions and includes the computing of the outranking flows. For each possible decision, the positive outranking flow $\varphi^{+}(a)$ and the negative outranking flow $\varphi^{-}(a)$ are computed. The positive outranking flow expresses how much each alternative is outranking all the others. The negative outranking flow expresses how much each alternative is outranked by all the others. $\varphi^{+}(a)=\frac{\pi(a, b)}{m-1}$

$\varphi^{-}(a)=\frac{\pi(b, a)}{m-1}$

where: $j=1, \ldots, m$ is the number of alternatives.

Step 4: This step is the second phase of determining the ranking of the criteria for each of the alternatives. The outranking flows are used to establish a complete ranking between the possible decisions. The net outranking flow $\varphi\left(a_{j}\right)$ of $a_{j}$ in the alternatives set $m$ of a possible decision is computed as a difference between $\varphi^{+}\left(a_{j}\right)$ and $\varphi^{-}\left(a_{j}\right)$.

$\varphi\left(a_{j}\right)=\varphi^{+}\left(a_{j}\right)-\varphi^{-}\left(a_{j}\right)$

For net outranking flow, the following conditions are valid:

$\varphi\left(a_{j}\right) \in[-1 ; 1]$

$\sum_{j=1}^{m} \varphi\left(a_{j}\right)=0$

The highest value of the net outranking flow shows the best decision.

\subsection{Step 3: Method for selecting the optimal transport plan}

The final phase of the methodology includes scheme selection. In the study, the full impact of all additional criteria is seen as a benefit to passengers. Thus, the costs are not introduced into the PROMETHEE model with a separate weight defined by the FAHP method. Their impact is examined separately, i.e., this research takes into account on the one hand the complex impact of the costs, and on the other hand the complex effect of the benefits. The optimal scheme is selected by the criterion minimum value of ratio $r_{f}$ of the normalized costs (received from direct operating costs given by fuzzy linear programming model) and the normalized scores corresponding to the PROMETHEE priority. The minimal value of this ratio presents the optimal scheme.

$r_{f}=\frac{c_{f}}{a_{f}} \rightarrow \min$

where: $c_{f}$ is the direct operating normalized costs for variant scheme $f ; a_{f}$ is the normalized net outranking flow by PROMETHEE method for variant scheme $f$; $f=1, \ldots, F$ is the number of variant schemes. To normalize each of the values of net outranking flow $\varphi_{f}$ obtained by PROMETHEE method, value $M$ is added, as the values of $\varphi_{f}$ are positive and negative.

$$
c_{f}=\frac{R_{f}}{\sum_{f=1}^{F} R_{f}}
$$




$$
a_{f}=\frac{\varphi_{f}+M}{\sum_{f=1}^{F}\left(\varphi_{f}+M\right)}
$$

where: $M$ is an integer and positive value that should make all net outranking flows $\varphi_{f}$ positive; $\varphi_{f} \in[-1 ; 1]$. For example, if the maximal negative value of $\varphi_{f}=-0.9$, the value of $M$ is $M=1$, and if the maximal negative value of $\varphi_{f}=-1$, the value of $M$ is $M=2$.

This integrated approach of multi-criteria decision technique and fuzzy linear programming method for choosing the optimal transport plan allows for the evaluation of the variant schemes according to the criterion of minimum direct operating costs and the complex criterion of the predefined indicators - the maximum PROMETHEE score. It enables reducing subjectivism when making a decision, i.e., it is a combination of an expert and optimization method, taking into account the economic and technological factors in choosing a transport plan. The sensitivity analysis of the methodology depends on the limits of variation of the criteria weights in which the optimal solution is retained.

\section{EXPERIMENTAL WORK AND RESULTS}

This integrated approach is applied to the railway network of Bulgaria in order to investigate the transport scheme of intercity trains. The present research examines nine schemes of organization of intercity passenger trains according to train categories and number of cars in the trains. In addition to the existing two categories of intercity trains in Bulgaria - faster
(TC3) and accelerated fast (express) trains (TC2) - we have studied another category of intercity trains - the so called direct (TC1) trains. Accelerated fast trains require a reservation and serve large intermediate stations between cities, big transport and important administrative centers. Direct trains also require reservation but operate between big transport and important administrative centers. The variants of the number of cars in a train composition are elaborated in terms of the size of passenger flow and the existing transport organization. Figure 1 presents the scheme of investigated itineraries marked from $\times 1$ to $\times 27$. The starting and final stations as well as the sections that are examined in the methodology are shown in this figure.

Scheme 1, Scheme 2, and Scheme 3 include three categories of intercity trains: direct fast trains (TC1) 3 itineraries, accelerated fast trains (TC2) - 7 itineraries, and fast trains (TC3) - 17 itineraries. The direct train service was studied for the Sofia-Burgas and Sofia-Varna railway stations, which are characterized by large passenger flows and transport centers. The total number of itineraries is 27 (from $x 1$ to $\times 27$ ). Scheme 4, Scheme 5, and Scheme 6 comprise service with two categories of intercity trains: TC1 - 3 itineraries, and TC3 - 17 itineraries. The total number of itineraries is 20 (from $\times 1$ to $\times 3$ for direct fast trains and from $\times 11$ to $x 27$ for fast trains.

Scheme 7, Scheme 8, and Scheme 9 include service with two categories of intercity trains: TC2 - 7 itineraries and TC3 - 17 itineraries. The total number of itineraries is 24 (from $\times 4$ to $\times 27$ for accelerated fast

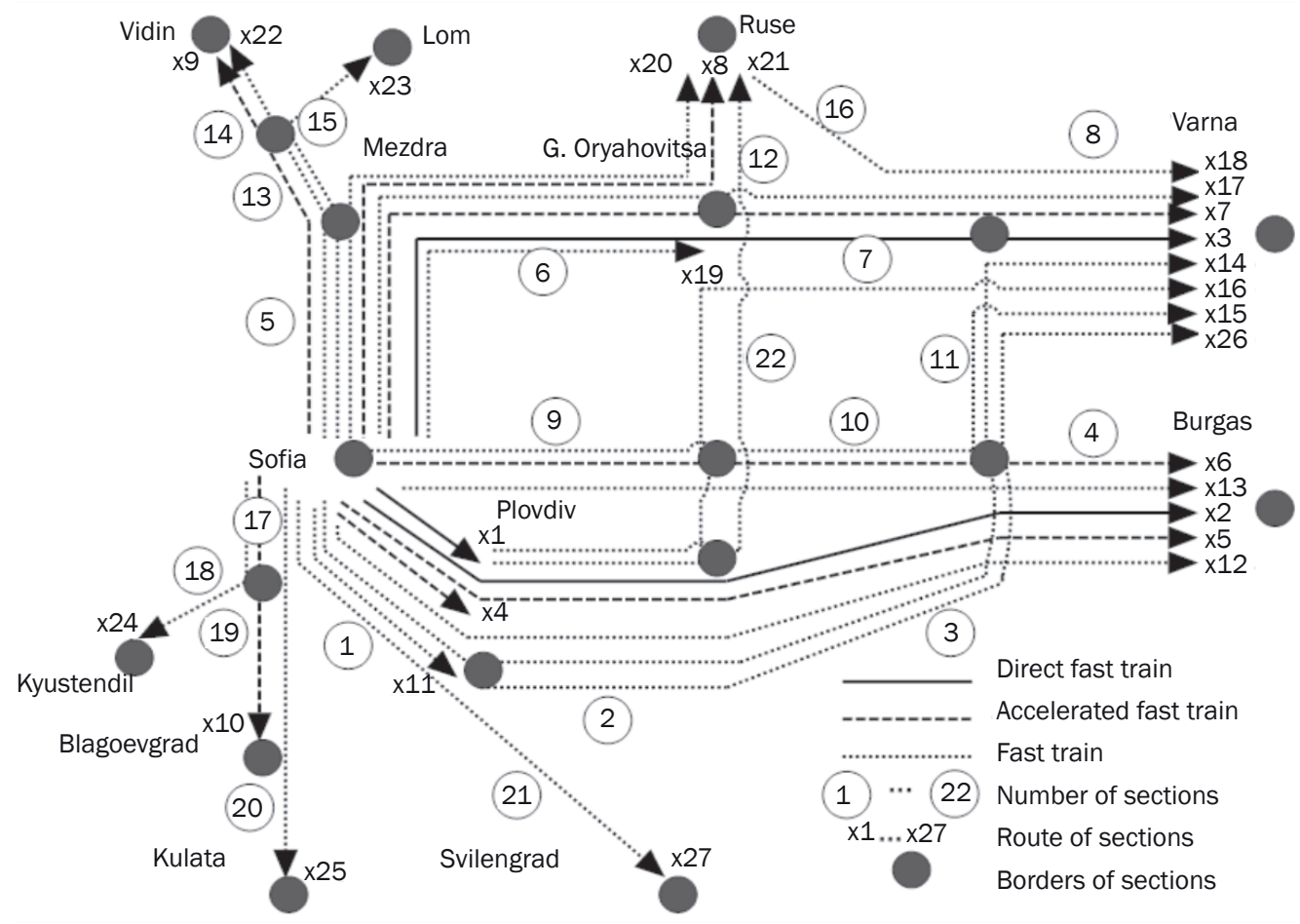

Figure 1 - Scheme of studied itineraries 
trains and fast trains). The number of cars in a train composition for schemes 1,4 , and 7 is 4 ; for schemes 2,5 , and 8 it is 3 cars. The number of cars for Scheme 3 is 3 for TC1 and 4 for TC2 and TC3; the number of cars for Scheme 6 is 3 for TC1 and 4 for TC3; the number of cars for Scheme 9 is 3 for TC2 and 4 for TC3.

In the first methodology step for each of the defined variant schemes, the fuzzy linear optimization model according to 2.1 is applied. The fuzzy numbers for passenger train capacity utilization coefficient are set taking into account the real utilization of trains by routes. For example, the fuzzy numbers are: for $x 1, x 2, x 3$ (0.55;0.65;0.8); from $x 4$ to $\times 10-(0.5 ; 0.6 ; 0.8)$; for $\mathrm{x} 15$ and $\mathrm{x} 26$ - (0.6;0.75;0.9); for x11, x19, x23, and x25 - (0.6;0.85;0.9); for all others - (0.6;0.8;0.9).

Table 2 presents the highest and lowest acceptable levels of the fuzzy quantities of passenger flows by investigated section. These levels are set separately by categories of trains which serve the sections. The upper and lower limits of change in passenger flows are set expertly after an analysis of a census of passengers for a period of one week in March, July, and October.

Table 3 shows the value of objective Function 9 and the number of trains in one direction for each variant scheme obtained by the fuzzy optimization model 9-12. The last row of the table presents the value of direct operating costs. Figure 2 shows the comparison of results obtained with individual optimization by linear model (for the highest and lowest acceptable levels of the fuzzy quantities of passenger flow presented in Table 2), and those obtained with fuzzy linear optimization. It can be seen that the results for the number of trains with fuzzy optimization are between the results received with individual optimization. This optimization approach takes into account the uncertainty of the processes and enables accounting for fluctuations in passenger flows.

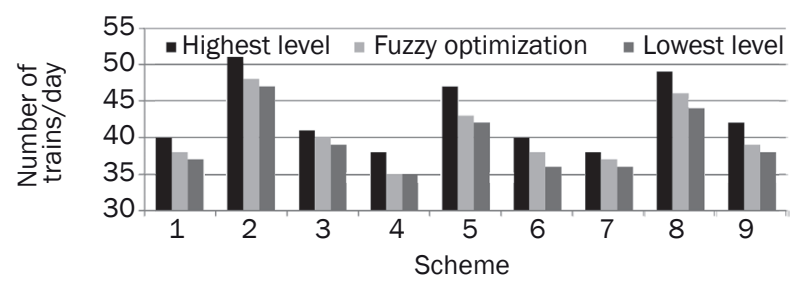

Figure 2 - Comparison of results by individual and fuzzy optimization

The second step of the methodology includes determination of the criteria values and prioritization of the criteria and variant schemes. The values of the criteria defined in 2.2.1 have been determined after optimization for each variant scheme. Table 4 presents the results. The value of criterion $K_{1}$ is given by fuzzy optimization model; the values of other criteria are calculated according to the parameters of the optimized variant scheme. To calculate the coefficient given in

Table 2 - Highest and lowest levels of fuzzy quantities of passenger flows

\begin{tabular}{|c|c|c|c|c|c|c|c|c|c|c|c|c|}
\hline \multicolumn{2}{|r|}{ Section } & 1 & 2 & 3 & 4 & 5 & 6 & 7 & 8 & 9 & 10 & 11 \\
\hline \multirow[t]{2}{*}{ TC1 } & $P_{i k, q, U}$, pass./day & 327 & 159 & 159 & 159 & 185 & 185 & 185 & 185 & & & \\
\hline & $P_{j k, q, L}$, pass./day & 277 & 122 & 122 & 122 & 150 & 150 & 150 & 150 & & & \\
\hline \multirow[t]{2}{*}{ TC2 } & $P_{j k, q, U}$, pass./day & 225 & 128 & 128 & 128 & 560 & 375 & 189 & 189 & 165 & 165 & \\
\hline & $P_{j k, q, L}$, pass./day & 195 & 108 & 108 & 108 & 487 & 323 & 166 & 166 & 137 & 137 & \\
\hline \multirow[t]{2}{*}{ TC3 } & $P_{i k, q, U}$, pass./day & 982 & 1176 & 620 & 774 & 1420 & 763 & 568 & 941 & 368 & 368 & 425 \\
\hline & $P_{i k, q . L}$, pass./day & 870 & 1046 & 540 & 680 & 1257 & 665 & 495 & 831 & 316 & 316 & 365 \\
\hline & Section & 12 & 13 & 14 & 15 & 16 & 17 & 18 & 19 & 20 & 21 & 22 \\
\hline \multirow[t]{2}{*}{ TC2 } & $P_{i k, q, U}$, pass./day & 105 & 182 & 182 & & & 139 & & 139 & & & \\
\hline & $P_{i k, q, L}$, pass./day & 85 & 159 & 159 & & & 117 & & 117 & & & \\
\hline \multirow[t]{2}{*}{ TC3 } & $P_{j k, q, U}$, pass./day & 372 & 759 & 557 & 99 & 371 & 845 & 325 & & 845 & 190 & 381 \\
\hline & $P_{j k, q, L}$, pass./day & 320 & 669 & 487 & 76 & 323 & 745 & 275 & & 745 & & 329 \\
\hline
\end{tabular}

Table 3 - Results by fuzzy linear optimization model

\begin{tabular}{||c|c|c|c|c|c|c|c|c|c||}
\hline Scheme & 1 & 2 & 3 & 4 & 5 & 6 & 7 & 8 & 9 \\
\hline \hline$\lambda$ & 0.528 & 0.414 & 0.485 & 0 & 0 & 0 & 0 & 0 & 0 \\
\hline TC1, train/day & 3 & 5 & 5 & 7 & 8 & 9 & 0 & 0 & 0 \\
\hline TC2, train/day & 8 & 10 & 8 & 0 & 0 & 0 & 9 & 13 & 11 \\
\hline TC3, train/day & 27 & 33 & 27 & 28 & 35 & 29 & 28 & 33 & 28 \\
\hline Total, train/day & 38 & 48 & 40 & 35 & 43 & 38 & 37 & 46 & 39 \\
\hline$R_{f}$ BGN/day & 51,583 & 57,234 & 52,615 & 48,772 & 53,639 & 51,159 & 49,716 & 54,073 & 50,232 \\
\hline
\end{tabular}


Table 4 - Criteria values

\begin{tabular}{||c|c|c|c|c|c|c|c||}
\hline Scheme & $\begin{array}{c}K_{1} \\
\text { [pair trains/day] }\end{array}$ & $\begin{array}{c}K_{2} \\
{[\text { stops/day] }}\end{array}$ & $\begin{array}{c}K_{3} \\
{[\mathrm{~km}]}\end{array}$ & $\begin{array}{c}K_{4} \\
{[\mathrm{~km} / \mathrm{h}]}\end{array}$ & $K_{5}$ & $K_{6}$ & $\begin{array}{c}K_{7} \\
\text { [seats/day] }\end{array}$ \\
\hline \hline 1 & 38 & 15.45 & 336.47 & 63 & 0.1315 & 1 & 10,640 \\
\hline 2 & 48 & 14.94 & 342.10 & 64 & 0.1347 & 1 & 10,080 \\
\hline 3 & 40 & 14.68 & 333.88 & 63 & 0.1336 & 1 & 10,850 \\
\hline 4 & 35 & 16.17 & 347.17 & 63 & 0.1329 & 1 & 9,800 \\
\hline 5 & 43 & 16.79 & 357.63 & 63 & 0.1424 & 1 & 9,030 \\
\hline 6 & 38 & 15.55 & 349.16 & 63 & 0.1323 & 1 & 10,010 \\
\hline 7 & 37 & 16.19 & 330.14 & 63 & 0.1248 & 0 & 10,360 \\
\hline 8 & 46 & 15.72 & 333.72 & 63 & 0.1296 & 0 & 9,660 \\
\hline 9 & 39 & 15.62 & 330.82 & 63 & 0.1235 & 0 & 10,150 \\
\hline
\end{tabular}

Formula 17, data for train delays up to 30 minutes over a three-year period was used. The criterion $\mathrm{K} 5$ is determined by Formula 16 using the predetermined coefficient from Formula 16 and the results of the optimization model from Step 1.

The criteria weights are obtained using the Fuzzy AHP method according to 2.2.2. Several studies reported AHP findings with different numbers of experts: 38 experts for 25 factors [7]; 7 experts for 31 factors [11], 20 experts for 43 factors [17]. Increasing the number of experts generally leads to increased reliability of expertise. The number of experts may be reduced if specialists with higher competence are selected. The number of experts can be reduced from 11 to 7 with the confidence level of $90 \%$ if they have high competency [20]. It is accepted that the optimal number of experts is in the range of 7 to 20 [20]. For this purpose, 7 experts, professionals from "BDZ - Passenger Transport" Ltd and Technical University Sofia with more than 20 years of experience in passenger railway transport, were asked to perform pairwise comparisons of all factors using the triangular fuzzy scale given in Table 1.

The pairwise comparison of the criteria is presented in Table 5.

Table 5 - Fuzzy evaluation - pairwise comparison matrix for criteria

\begin{tabular}{|c|c|c|c|c|c|c|c|c|c|}
\hline Criterion & Triangular fuzzy numbers & & & & & & & & Weight \\
\hline \multirow{3}{*}{$K_{1}$} & $l$ & 1 & 0.39 & 0.32 & 1.27 & 1.00 & 1.08 & 0.37 & \multirow{3}{*}{0.15} \\
\hline & $m$ & 1 & 0.70 & 0.64 & 1.87 & 1.27 & 1.87 & 0.70 & \\
\hline & $u$ & 1 & 1.00 & 1.00 & 3.50 & 3.11 & 3.65 & 1.00 & \\
\hline \multirow{3}{*}{$K_{2}$} & $l$ & 1 & 1 & 0.41 & 1.40 & 1.00 & 1.00 & 0.37 & \multirow{3}{*}{0.08} \\
\hline & $m$ & 1.43 & 1 & 0.78 & 3.00 & 1.27 & 1.27 & 0.70 & \\
\hline & $u$ & 2.57 & 1 & 1.00 & 5.12 & 1.87 & 1.87 & 1.00 & \\
\hline \multirow{3}{*}{$K_{3}$} & $l$ & 1.00 & 1.00 & 1 & 1.08 & 1.00 & 1.08 & 1.00 & \multirow{3}{*}{0.07} \\
\hline & $m$ & 1.57 & 1.29 & 1 & 2.15 & 1.40 & 2.15 & 1.27 & \\
\hline & $u$ & 3.14 & 2.43 & 1 & 4.20 & 2.33 & 4.20 & 2.71 & \\
\hline \multirow{3}{*}{$K_{4}$} & $l$ & 0.29 & 0.20 & 0.24 & 1 & 0.39 & 0.44 & 0.23 & \multirow{3}{*}{0.22} \\
\hline & $m$ & 0.54 & 0.33 & 0.46 & 1 & 0.70 & 0.70 & 0.41 & \\
\hline & $u$ & 0.79 & 0.71 & 0.93 & 1 & 1.00 & 1.00 & 0.78 & \\
\hline \multirow{3}{*}{$K_{5}$} & $l$ & 0.32 & 0.54 & 0.43 & 1.00 & 1 & 1.00 & 0.30 & \multirow{3}{*}{0.17} \\
\hline & $m$ & 0.79 & 0.79 & 0.71 & 1.43 & 1 & 1.17 & 0.64 & \\
\hline & $u$ & 1.00 & 1.00 & 1.00 & 2.57 & 1 & 1.75 & 1.00 & \\
\hline \multirow{3}{*}{$K_{6}$} & $l$ & 0.27 & 0.26 & 0.24 & 1.00 & 0.57 & 1 & 0.29 & \multirow{3}{*}{0.22} \\
\hline & $m$ & 0.54 & 0.50 & 0.46 & 1.43 & 0.86 & 1 & 0.64 & \\
\hline & $u$ & 0.93 & 0.86 & 0.93 & 2.29 & 1.00 & 1 & 1.00 & \\
\hline \multirow{3}{*}{$K_{7}$} & $l$ & 1.00 & 1.00 & 0.37 & 1.29 & 1.00 & 1.00 & 1 & \multirow{3}{*}{0.10} \\
\hline & $m$ & 1.43 & 1.43 & 0.79 & 2.43 & 1.57 & 1.57 & 1 & \\
\hline & $u$ & 2.71 & 2.71 & 1.00 & 4.29 & 3.29 & 3.43 & 1 & \\
\hline
\end{tabular}


The consistency ratio value is 0.1 , which shows that the experts' assessments are reliable. The values of each of the triangular fuzzy numbers (the least possible value $l$, the most possible value $m$, and the largest possible value $u$ ) have been determined as average values obtained from the estimates made by the experts.

The average speed and availability of service with direct transport criteria have the greatest weight. The criteria of transport satisfaction and reliability are also of great importance. Table 4 shows that the average speed criterion values for all variant schemes are similar. This is due to the small number of direct trains. The average speed value for the variant scheme increases with increased number of direct trains.

The prioritization of variant schemes is made using the PROMETHEE method according to 2.2.3. The type of optimization is: maximum for the criteria $K_{1}$ (transport capacity), $K_{3}$ (average vehicle distance), $K_{4}$ (average speed), $K_{6}$ (presence of direct transport), and $K_{7}$ (transport capacity); minimum for the criteria $K_{2}$ (average number of stops), and $K_{5}$ (reliability factor by Formulas 16 and 17). The type of preference functions is: for criterion $K_{6}$ - Usual; for all other criteria - Linear. The usual function is best suited for quality criteria that are set to "Yes" and "No". Linear functions are typically used for quantitative criteria.

The third step of the methodology includes scheme selection. The Visual PROMETHEE software was used to rank the variant schemes. Figure 3 presents normalized costs, normalized PROMETHEE net outranking flow, and the criterion of optimization - value of the ratio of normalized costs/normalized PROMETHEE scores given by Formulas 29-31 of all variant schemes when changing passenger flows.

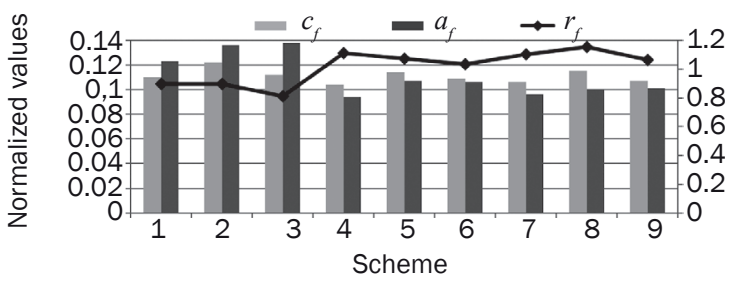

Figure 3 - Normalized costs $c_{p}$, normalized PROMETHEE net outranking flow $a_{f}$, criterion of optimization $r_{f}$
The results show that, in terms of minimum direct operating costs, the optimal variant scheme is number 4 (TC1 and TC3 with 4 cars); in terms of maximum PROMETHEE score, the optimal variant scheme is number 3 (TC1 - 3 cars; TC2 - 4 cars; TC3 - 4 cars). The optimal variant scheme using a ratio of normalized costs/normalized net outranking flow by PROMETHEE scores is once again Scheme 3, where direct trains are composed of 3 cars, while accelerated fast and fast trains are composed of 4 cars.

A sensitivity analysis of the optimal solution was conducted. The research shows that the more sensitive criteria are those of transport satisfaction $K_{1}$, average distance traveled $K_{3}$, and transport capacity $K_{7}$. The percentages of criteria variation at which the decision is unchanged are respectively: $K_{1}-[6.53 \%-$ $16.7 \%$ ]; $K_{3}$-[3.95\%-24.14\%] and $K_{7}$-[8.12\%-22.54\%]. All other criteria have limits of change from $0 \%$ to $100 \%$. Figure 4 presents a sensitivity analysis of the optimization criterion $r_{f}$. The results are obtained depending on the limits of variation of the weights of the criteria given above. It can be seen that the optimal scheme is the third one, i.e., the optimal solution remains unchanged.

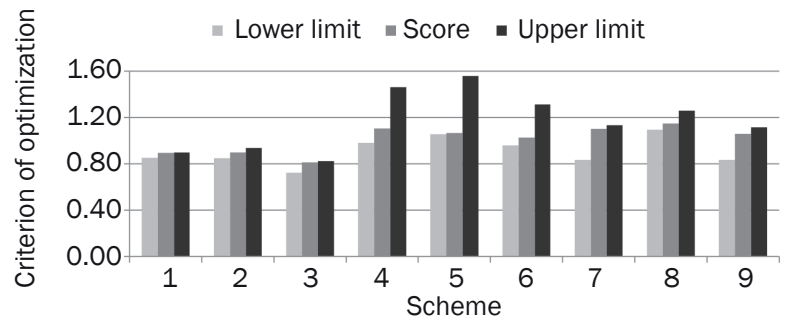

Figure 4 - Sensitivity analysis of the optimization criterion

Table 6 presents a comparison of the results for main train routes. The optimal solution proposes service with three categories of intercity passenger trains. The number of trains for the routes Sofia-Plovdiv and Sofia-Plovdiv-Burgas is increased. The number of trains for the route Sofia-Plovdiv-Burgas is increased by offering additional direct trains. The number of trains for the route Sofia-G. Oryahovitsa-Varna is retained, but the categories are different.

Figure 5 shows a comparison of results and real situation for main routes with the largest passenger flow. The section from Sofia to Plovdiv serves train routes

Table 6 - Comparison of results for main train's routes

\begin{tabular}{|c|c|c|c|c|c|c|c|c|}
\hline \multirow{3}{*}{ Train route } & \multicolumn{8}{|c|}{ Train category [pair trains/day] } \\
\hline & \multicolumn{4}{|c|}{ Optimal variant scheme } & \multicolumn{4}{|c|}{ Timetable } \\
\hline & TC1 & TC2 & TC3 & Total & TC1 & TC2 & TC3 & Total \\
\hline Sofia-Plovdiv & 1 & 1 & 2 & 4 & 0 & 0 & 3 & 3 \\
\hline Sofia-Plovdiv-Burgas & 2 & 1 & 2 & 5 & 0 & 1 & 3 & 4 \\
\hline Sofia-G. Oryahovitsa-Varna & 2 & 1 & 2 & 5 & 0 & 1 & 4 & 5 \\
\hline
\end{tabular}




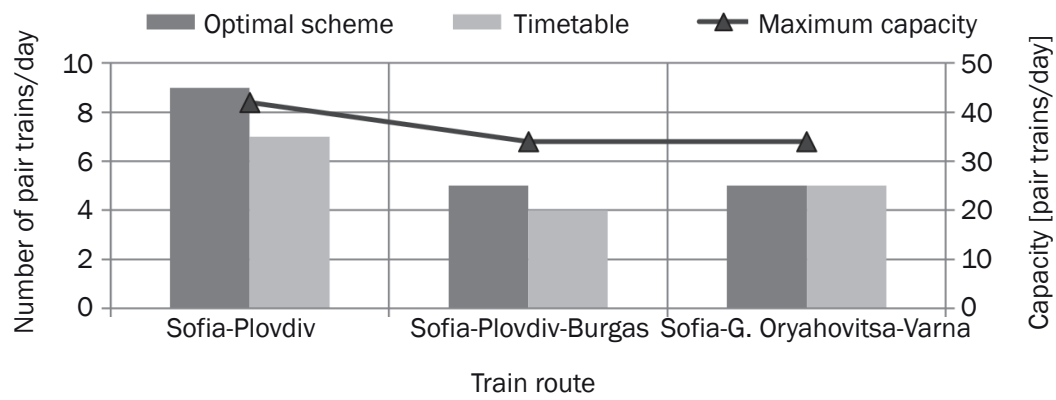

Figure 5 - Comparison of results for main routes

Sofia-Plovdiv and Sofia-Plovdiv-Burgas. Figure 5 presents the total number of trains from both destinations. The maximum capacity for all categories of passenger trains including ordinary passenger trains and suburban trains for these routes are: Sofia-Plovdiv - 42 pair trains/day; Sofia-Plovdiv-Burgas - 34 pair trains/day; Sofia-G. Oryahovitsa-Varna - 34 pair trains/day. These destinations are also served by freight trains.

The optimal variant scheme offers an increase in the train transport service, thus reducing the direct operating costs as compared to the existing situation. The proposed number of trains is 80 trains/day versus 75 trains/day in the current situation. This number of trains corresponds to the available rolling stock. The proposed scheme differs by category and composition from the existing train timetable.

\section{CONCLUSIONS}

In this research, we have elaborated an integrated approach based on the fuzzy optimization and combined multi-criteria methods for determining the optimal scheme of movement of intercity trains on the railway network. This approach makes it possible to take into account not only economic criteria, such as direct operating costs, but also additional technological factors related to the transportation process. The fuzzy linear programming method has been applied to optimize the transportation scheme for intercity trains in terms of direct operating costs taking into account the uncertainty of the process through the highest and lowest levels of the fuzzy quantities of passenger flows and triangular fuzzy numbers for utilization of train capacity. In the research, additional criteria have been determined to assess the schemes of transportation. They have been evaluated using the Fuzzy AHP method. The study shows that average speed $(0.22)$, availability of service with direct transport $(0.22)$, reliability (0.17), and transport satisfaction (0.15) are the most important criteria when determining the transport scheme. Nine schemes of transportation by intercity passenger trains have been investigated according to train category and number of cars in a train composition. A combined method of Fuzzy AHP and PROMETHEE has been applied to evaluate variant schemes by additional criteria. The ratio of normalized costs and normalized PROMETHEE net outranking flow has been applied as a criterion for choosing the optimal scheme of transportation.

The proposed methodology can facilitate decision-making in route and schedule planning and additional routing related to increased passenger traffic due to extraordinary situations in stations.

СВЕТАА СТОИЛОВА, АОЦ. А-р

E-mail: stoilova@tu-sofia.bg

Технически Университет-София, Факултет по транспорт бул.Климент ОхриАски 8, София 1000, България

\section{ИНТЕГРИРАН ПОАХОА ЗА ИЗБОР НА СХЕМА ЗА ПРЕВОЗ НА ВААКОВЕ В ЖЕАЕЗОПЪТНАТА МРЕЖА}

\section{PEЗЮME}

Основен проблем, свързан с планирането на организацията на влаковете в железопътната мрежа, е оптимизацията на схемата на Авижение, която определя маршрута и броя на влаковете. В тази статия се предлага интегриран подхоА от размит минеен оптимизационен модел и многокритериален анализ, включващ три стьпки. В първата стьпка са определени схеми за превоз на междуградски влакове, и е оптимизирана всяка схема по отношение на преките експлоатационни разходи, като е отчетена неопределеността на пътникопотоците и използването на капацитета на влаковете, чрез прилагане на размито минейно оптимиране. Във втората стъпка са определени допълнителни технологични критерии за оценка на вариантните схеми. За определяне на теглата на критериите е приложен методът Fuzzy AHP. Използвайки резултатите, получени от Fuzzy AHP, са приоритизирани различните варианти чрез прилагане на метода PROMETHEE. Третата стьпка представя оптималния избор на схема за превоз на влаковете в железопътната мрежа, по критерий минимум на съотношението на нормализираните разходи и нормализираните аутранкиращи потоци по метода PROMETHEE. В тази стьпка моделът използва резултатите, получени в първата и втората стьпка. Приложимостта на интегрирания подхоА е показана чрез пример за железопътната мрежа на България, като са изследвани девет схеми. Резултатите от модела са сравнени със съществуващото положение. Установено е, че оптималната схема за превоз на междуградските влакове предлага увеличаване на 
транспортното обслужване с влакове и намалява преките експлоатационни разходи.

\section{КАЮчОВИ АУМИ}

размито минейно оптимиране; Fuzzy AHP; PROMETHEE; влак; пътник;

\section{REFERENCES}

[1] Guzman V, Masegosa A, Pelta D, Verdegay J. Fuzzy Models and Resolution Methods for Covering Location Problems: an Annotated Bibliography. Int. J. Unc. Fuzz. Knowl. Based Syst. 2016;24(4): 561-591. doi:10.1142/S0218488516500276

[2] Verdegay J. Progress on Fuzzy Mathematical Programming: A personal perspective. Fuzzy Sets and Systems. 2015;281: 219-226. doi:10.1016/j.fss.2015.08.023.

[3] Li W, Qin Y, Xu J, Jia L. A Fuzzy Optimization Model for High-Speed Railway Timetable Rescheduling. Discrete Dynamics in Nature and Society. 2012; Article ID 827073:1-22.doi.org/10.1155/2012/827073

[4] Meng X, Jia L, Xiang W, Xu J. Train re-scheduling based on an improved fuzzy linear programming model. Kybernetes. 2015;44(10): 1472-1503. doi:10.1108/K-10-2014-0226

[5] Chang $\mathrm{Y}-\mathrm{H}$, Yeh $\mathrm{C}-\mathrm{H}$, Shen C-C. A multiobjective model for passenger train services planning: application to Taiwan's high-speed rail line. Transportation Research Part B: Methodological. 2000;34(2): 91-106. doi: 10.1016/S0191-2615(99)00013-2.

[6] Khan AJ, Das DK. Fuzzy multi objective optimization: With reference to multi objective transportation problem. Recent Research in Science and Technology. 2014;6(1): 274-282. [cited 20 July 2017] Available from: https://scienceflora.org/journals/index.php/rrst/ article/viewFile/1215/1201

[7] Diaz-Madronero M, Peidro D, Mula J. A fuzzy optimization approach for procurement transport operational planning in an automobile supply chain. Applied Mathematical Modelling. 2014;38: 5705-5725. doi:10.1016/j.apm.2014.04.053

[8] Brito J, Moreno JA, Verdegay J. Transport route planning models based on fuzzy approach. Iranian Journal of Fuzzy Systems. 2012;9(1): 141-158. Available from: http://ijfs.usb.ac.ir/pdf_231_7ebf6519fbcb9484fdaa9a6e8d293100.html

[9] Kovačić M. Selecting the location of a nautical tourism port by applying PROMETHEE and GAIA methods case study - Croatian northern Adriatic. Promet - Traffic \& Transportation. 2010;22(5): 341-351. doi:10.7307/ ptt.v22i5.199

[10] Tadić S, Zečević S, Krstić M. Ranking of logistics system scenarios for central business district.
Promet - Traffic \& Transportation. 2014;26(2): 159167. doi:10.7307/ptt.v26i2.1349.

[11] Deng $H$, Zhang Z. GIS-based combination of fuzzy numbers and AHP method for selection of highway route: a case study from Anhui. Proceedings of the International Conference on Mechanic Automation and Control Engineering (MACE); 2010 Jun 26-28; Wuhan, China: IEEExpore.760-764. doi:10.1109/ MACE.2010.5535824.

[12] Isaai $M$, Kanani $A$, Tootoonchi $M$, Afzali $H$. Intelligent timetable evaluation using fuzzy AHP. Expert Systems with Applications. 2011;38: 3718-3723. doi:10.1016/j.eswa.2010.09.030

[13] Kazan H, Ciftci C. Transport Path selection: Multi-Criteria Comparison. International Journal of Operations and Logistics Management. 2013;2(4): 33-48. [cited 20 July 2017] Available from: http://www.academia. edu/5300413/Transport_Path_Selection_Multi-Criteria_Comparison

[14] Wen H, Lin S. Performance Evaluation of Highway Passenger Transport Enterprises' Operation based on the Model of AHP-DEA. Industrial Engineering and Engineering Management, IEEE $18^{\text {th }}$ International Conference; 2011 Aug 12-14; Wuhan, China. 2:811-815. doi: 10.1109/ICMSS.2011.5998823

[15] Abramović B. Passenger's satisfaction on long distance terminals: Case study city of Zagreb. Periodica Polytechnica Transportation Engineering. 2017;46(1): 42-47. doi:10.3311/PPtr.9197.

[16] Macharis C, Springael J, De Brucker K, Verbeke, A, PROMETHEE and AHP: The design of operational synergies in multicriteria analysis: Strengthening PROMETHEE with ideas of AHP. European Journal of Operational Research. 2004;153: 307-317. doi:10.1016/ S0377-2217(03)00153-X.

[17] Chang D. Applications of the Extent Analysis Method on Fuzzy AHP. European Journal of Operational Research. 1996;95(3): 649-655. doi:10.1016/03772217(95)00300-2.

[18] Saaty T. Fundamentals of the Analytic network process - Dependence and feedback in decision-making with a single network. Journal of Systems Science and Systems Engineering. 2004;1: 129-157. doi:10.1007/ s11518-006-0158-y.

[19] Brans JP. Mareschal B. PROMETHEE Methods. In: Multiple Criteria Decision Analysis: State of the Art Surveys. International Series in Operations Research \& Management Science. 2005;78: 163-186. doi: 10.1007/0-387-23081-5 5.

[20] Christova M. [Expert evaluation of quality of education in higher schools and methods for its objectification]. Mechanics, Transport, Communications. 2007;1: 14. Bulgarian. 